This is an author produced version of a paper published in Livestock Science.

This paper has been peer-reviewed but may not include the final publisher proof-corrections or pagination.

Citation for the published paper:

Kaari Reimus, Toomas Orro, Ulf Emanuelson, Arvo Viltrop, Kerli Mõtus. (2017) Reasons and risk factors for on-farm mortality in Estonian dairy herds. Livestock Science. Volume: 198, pp 1-9. http://dx.doi.org/10.1016/j.livsci.2017.01.016.

Access to the published version may require journal subscription.

Published with permission from: Elsevier.

Standard set statement from the publisher:

(C) Elsevier, 2017 This manuscript version is made available under the CC-BY-NC-ND 4.0 license http://creativecommons.org/licenses/by-nc-nd/4.0/

Epsilon Open Archive http://epsilon.slu.se 


\section{Reasons and risk factors for on-farm mortality in Estonian dairy herds}

Kaari Reimus $^{\text {a* }}$, Toomas Orro ${ }^{\mathrm{a}}$, Ulf Emanuelson ${ }^{\mathrm{b}}$, Arvo Viltrop ${ }^{\mathrm{a}}$, Kerli Mõtus ${ }^{\mathrm{a}}$

anstitute of Veterinary Medicine and Animal Sciences, Estonian University of Life Science

Kreutzwaldi 62, 51014, Tartu, Estonia

${ }^{b}$ Department of Clinical Sciences, Swedish University of Agricultural Sciences

P.O. Box 7054, SE-750 07 Uppsala, Sweden

Authors contacts:

Toomas.Orro@emu.ee

Ulf.Emanuelson@slu.se

Arvo.Viltrop@emu.ee

Kerli.Motus@emu.ee

*Corresponding author: Kaari Reimus, tel.: +372 55618085, e-mail: Kaari.Reimus@emu.ee 


\begin{abstract}
Mortality of dairy cattle causes financial loss for the farmer and reflects animal welfare status. The aim of this study was to determine the on-farm mortality (unassisted death and euthanasia), reasons, as well as risk factors for on-farm mortality in Estonian dairy cattle. Data of years 2013 and 2014 about all cattle from dairy herds in Estonia was collected from the Estonian Agricultural Registers and Information Board. The dataset included records of 363,380 animals from 2,616 herds. Multivariable Weibull proportional hazard models with herd as random effect were composed for detecting significant associations between potential risk factors and on-farm mortality (composed outcome including unassisted death and euthanasia). Data from Estonian Livestock Performance Recording Ltd was used to determine the reasons for on-farm mortality.

The overall mortality rate (MR) including unassisted death and euthanasia was 6.95 per 100 animal-years. Mortality was highest in male (MR $=55.96$ per 100 animal-years, 95\% CI 54.53; 57.42) and female ( $M R=27.70$ per 100 animal-years, 95\% CI 26.99; 28.43) calves up to three months old and lowest in female cattle aged 12-18 months (MR $=0.99$ per 100 animal-years, 95\% CI $0.89 ; 1.10)$. The main farmers' stated reasons for dairy cow mortality were 'Metabolic and digestive disorders' and 'Feet/claw disorders'. The main reasons for on-farm mortality among youngstock were 'Metabolic and digestive disorders', 'Respiratory and infectious diseases' and 'Other reasons'. The risk factor analysis was carried out in three age categories: $<3$ months, 3-23 months and $\geq 24$ months. Estonian Holstein breed was associated with significantly higher risk of mortality compared to Estonian Red breed cattle in every age group. The hazard of on-farm mortality was significantly higher for herds with over 400 animal-years compared to smaller herds in all age groups. Regional differences in mortality hazard were present in the model of youngstock over 3 months and adult cattle. Seasonal differences in mortality rate were present and differed by age groups.

This is the first study revealing the on-farm mortality and related risk factors in Estonian dairy cattle population.
\end{abstract}

Keywords: dairy cattle, mortality, unassisted death, euthanasia, survival analysis 


\section{Introduction}

Increasing on-farm mortality among dairy cattle has been reported in several countries (Thomsen et al., 2006; McConnel et al., 2008). On-farm mortality is associated with economical loss for the farmer resulting from direct and indirect losses. On farms with high mortality there is higher incidence of diseases and higher costs for treatment (Azizzadeh et al., 2012). Also, a higher demand for replacement animals associated with additional cost for buying and raising offspring is an inherent consequence for such herds. Restricted voluntary culling due to high demand of replacement animals can lead to deterioration in the productivity of the herd. Cattle mortality is also an indicator of animal welfare (Thomsen and Houe, 2006; Oritz-Pelaez et al., 2008; Raboisson et al., 2011).

Mortality of dairy cows has been reported in the range of 3.5 to $6.1 \%$ in previous studies conducted in different countries (Thomsen et al., 2004; McConnel et al., 2008; Raboisson et al., 2011; Alvåsen et al., 2014), mortality of youngstock has been reported from 2.4 to 9.4\% (Losinger and Heinrichs, 1997; Gulliksen et al., 2009; Bleul, 2011; Azizzadeh et al., 2012, Santman-Berends et al., 2014). Previous studies have identified several animal level risk factors associated with dairy cow mortality hazard, e.g. milk yield, age at first calving, calving season, lactation stage and calving ease (McConnel et al., 2008; Alvåsen et al., 2012). Herd-level risk factors e.g herd size, region, predominant breed in the herd, herd milk yield, grazing, proportion of purchased animals have shown to influence dairy cow mortality (Thomsen et al., 2006; Burow et al., 2011; Raboisson et al., 2011; Alvåsen et al., 2012). Some examples of animal level risk factors associated with calf and youngstock mortality are breed, gestation length, parity of the dam, dystocia, being born as a twin or triplet, congenital defects, calving season, sex and weight of the calf, respiratory disease, diarrhea and arthritis (Svensson et al., 2006; Gulliksen et al., 2009; Bleul, 2011; Raboisson et al., 2013). Few examples of herd-level risk factors for calf mortality are herd size, characteristics of calving stall, suckling as feeding regimen and housing system from 2 weeks of age (Gulliksen et al., 2009). Raboisson et al. (2011) suggested that farmers' management style highly influences mortality and it is generally assumed that about half of the deaths can be prevented by proper management (McConnel et al., 2008, Santman-Berends et al., 2014).

Awareness of the mortality causes would enable to focus on preventing the predisposing factors that induce morbidity and mortality. Alvåsen et al. (2014) identified reasons for dairy cow on-farm mortality being fertility disorders, udder disorders, metabolic disorders, feet/claw disorders, trauma and other/unknown reasons. Reasons for youngstock mortality included enteritis, pneumonia, trauma and calving related diseases (Svensson et al., 2006).

Existence of national registry databases provides a good source of data that can be used to assess mortality. Despite availability of data, representative overviews over mortality rates in cattle populations of countries are few (Pannwitz, 2015). Still, in the last decade, some countries are developing surveillance systems using national registry mortality data for the detection of early disease outbreaks (Struchen et al., 2015; Torres et al., 2015; Santman-Berends et al., 2016). There is no normal level for on-farm mortality in cattle herds, but increasing trend of mortality in dairy herds has been reported in several studies (Thomsen et al., 2004; McConnel et al., 2008; Raboisson et al., 2011; Alvåsen et al., 2012; Alvåsen et al., 2014). Increasing on-farm mortality causes concerns about dairy cattle welfare.

Estonian dairy cattle operations are relatively large in size. According to the Estonian Agricultural Registers and Information Board (2016) $82 \%$ of dairy cows were kept in herds $>100$ cows. 
Substantial investments have been made in recent decades in housing and milking technology (loose housing open air barns and robotic milking systems). The national average milk production per cow has increased each year and has been $>8,000 \mathrm{~kg}$ during the last four years (Estonian Animal Recording Yearbook 2015). Estonia is in the $6^{\text {th }}$ place in the European Union by level of milk production per cow (Eurostat, 2015). Large dairy operations are managed by paid labour in contrast to smaller family farms. Thus, the present study provides relevant information on cattle mortality in a cattle population with an intensive production system and relatively large herds.

Objectives of this study were to assess on-farm mortality (unassisted death and euthanasia) in Estonian dairy cattle and characterize it by animal cohorts as well as identify the frequency of reported reasons of mortality. 


\section{Materials and methods}

\subsection{Study population}

Data about all cattle present in Estonian Farm Animal Register kept by the Estonian Agricultural Registers and Information Board (government agency, referred as "animal register" hereinafter) and the Estonian Livestock Performance Recording Ltd (national milk recording centre including $\sim 95 \%$ of all dairy cows in Estonia, referred as "milk recording register" hereinafter) was retrieved for the study period from $1^{\text {st }}$ of January 2013 to $31^{\text {st }}$ of December 2014. "Dairy herd" was defined as a herd with more than $75 \%$ of dairy breed cows. According to this definition the median proportion of beef breeds in the herds was $0 \%$ (range $0-24.4 \%$ ). A dataset was compiled including data of all animals in Estonian dairy herds present in the population on the $1^{\text {st }}$ of January 2013, and animals born and imported between $1^{\text {st }}$ of January 2013 and $31^{\text {st }}$ of December 2014 . The dataset included 363,380 animals from 2,616 herds, in total. Animal register data contained information about animal identification number, birth date, breed and sex of an animal, farm identification number together with owner's name, location of herd and exit date from herd, together with a type of exit (death on farm, euthanasia, slaughter, disappearance, diagnostic slaughter, slaughter/killing to prevent disease spread and export). Animal register data, containing information about the whole dairy cattle population, was used to calculate mortality rates and to perform risk factor analysis.

The milk recording register includes data about the reasons for animal exits stated by the farmers. In order to describe reasons for each mortality event milk recording register data was combined with animal register data. In the milk recording register dataset it is possible that one animal has several exit events (e.g. heifers moving to production herd, animal is sold to another herd as well as reasons for death or slaughter). To identify the reason for each mortality event, the date of the event in the milk recording register and animal register datasets were compared. Farmers are obliged by law to report the births, movements and exits of animals to animal register within 7 days (Riigi Teataja, 1999) whereas the data collected by the milk recording register are usually forwarded by the farmers once a month at the time of milk recording. This time difference in reporting the events to two different registers may cause some discrepancies in dates of exit events. Taking that into account, a difference of up to seven days in dates of the two datasets was allowed. The study population to identify reasons for death included all animals from milk recording register consisting of approximately $95 \%$ of all dairy cattle in Estonia. In case of exit of an animal farmer could select only one reason from the list given by the registry. Farmers' stated reasons for unassisted death and euthanasia of cows in milk recording register were categorized into following categories:

- Feet/claw disorders: included farmers' stated reasons - leg conformation flaws, leg traumas, leg disorders.

- Respiratory and infectious diseases: respiratory diseases, infectious diseases.

- Metabolic and digestive disorders: metabolic disorders, milk fever, digestive disorders.

- Fertility problems: fertility problems, gynecological diseases, abortion.

- Dystocia.

- Trauma and accident: other traumas, accident.

- Udder disorders: udder flaws, udder and teat traumas, mastitis.

- Other reasons.

- Unknown reasons: reasons that were rarely reported and could not be reasonably associated with mortality and were considered to be accidentally selected in reporting, e.g. age, low production, bad temperament, bad milking, moving into production herd, conformation flaws. 
For youngstock the farmers' stated reasons for unassisted death and euthanasia were categorized into the following categories:

- Feet/claw disorders.

- Respiratory and infectious diseases: respiratory diseases, infectious diseases.

- Metabolic and digestive disorders: metabolic disorders, digestive disorders.

- Fertility problems: fertility problems, abortion (for heifers only).

- Trauma and accident: trauma, accident.

- Other reasons.

- Unknown reasons.

\subsection{Statistical analyses}

For risk factor analysis the observation period started from $1^{\text {st }}$ of January 2013 and lasted until the failure (unassisted death or euthanasia) or censoring (slaughter, export or end of the study period). The study population was categorized into three breed categories: Estonian Holstein, Estonian Red and other breeds (included Estonian Native, Swiss, Aubrac, Aberdeen Angus, Blonde d Aquitaine, Belgian Blue, Charolais, Dexter, Ayrshire, Galloway, Scottish Highland, Hereford, Jersey, Limousine, Piemontese, Bison, German Shorthorn and Simmental cattle). Due to the relatively small number of animals in the category 'Other breeds' the category was not interpreted but the animals were retained in the analysis in order to evaluate the associations in terms of other risk factors. Variable 'herd size' was created based on a number of animal-years (including cattle of all ages) in total per calendar year and four categories were made by splitting in approximate quartile values: herds with 1-399, 400-899, 900-1499 and more than 1500 animal-years. Counties were compiled into four regions: Northeast, Southeast, Southwest and Northwest region. A time-varying covariate 'age category' was created by applying the stsplit command in Stata programme. Mortality rate (calculated as number of deaths per 100 animal-years) in female animals was calculated in seven age groups: $<3$ months, 3-5 months, 6-11 months, 12-17 months, 18-23 months, 24-35 months and $\geq 36$ months. Due to lower number of older male cattle, the mortality rates were calculated for four age categories: $<3$ months, 3-5 months, 6-11 months and $\geq 12$ months.

Survival analysis was applied in order to identify the mortality rate, whereas left truncation of the data was taken into account by defining the date when the animals entered the study (Cain et al., 2011). The date the animal entered the study was $1^{\text {st }}$ of January 2013, for animals already present in the population at that date, birth date for animals born during the study period and date of purchase for imported animals. Multivariable Weibull proportional hazard models with herd as a gamma distributed frailty effect were composed for detecting significant associations between potential risk factors and on-farm mortality. Different distributions of the parametric survival models were compared and Weibull distribution was chosen based on AIC and BIC values. Due to different baseline risk of different age categories the risk factor analysis was done separately in three age categories: calves aged $<3$ months (Model I), youngstock 3-23 months (Model II) and cattle aged $\geq 24$ months (Model III). Animals accumulated time at risk in its' age category until failure, censoring or moving to the next age category. Variables of interest in the analysis were age category, breed, sex, herd size and region and all variables were included to the multivariable model. All biologically plausible interactions between explanatory variables were tested and significant interactions were included as separate variables in the multivariable model. In order to detect confounding effects of the variable the change of regression coefficients was observed after removing it. Change in regression coefficients of more than $20 \%$ of the remaining variables in the 
model was indicative for confounding and the variable was retained in the model to control for its confounding effect (Dohoo et al., 2009). The fit of the models was evaluated visually in the plots of the cumulative hazard versus Cox-Snell residuals. Proportional hazards assumption was evaluated by visual inspection of log-cumulative hazard plots (Dohoo et al., 2009).

Seasonal distribution of mortality was analysed in four age groups: calves aged $<3$ months, youngstock 3-11 months, youngstock 12-23 months and cattle aged $\geq 24$ months by using survival analysis as described above. In each age category the observation period of each animal was split at the first day of each calendar month. Mortality rate was calculated for each month of the twoyear study period. In order to detect changes between mortality hazards of adjacent months an univariable Weibull proportional hazard model with month as hierarchical predictor and farm as random effect was composed.

All statistical analyses were performed using STATA MP version 14 (StataCorp LP, College Station, USA). 


\section{Results}

\subsection{Descriptive statistics}

During the 2013 and 2014 (24 months) study period, there were 363,380 animals in total included in the analysis. Among those, 26,088 (7.2\%) died, 600 (0.2\%) were euthanised, 60,059 (16.5\%) animals were slaughtered, 82,652 (22.7\%) were sold abroad, $356(0.1 \%)$ disappeared and 3 animals were slaughtered for diagnostic purposes. A total of 193,622 (53.3\%) animals survived until the end of the study period and were right censored. On-farm mortality (including unassisted death and euthanasia) rate (MR) per 100 animal-years was 6.95 (95\% confidence interval (CI) 6.87; 7.04). Mortality rate estimates together with number of animals in each category of breed, sex, herd size and region across the three age groups are shown in Supplementary Table 1.

Mortality rate estimates for female and male cattle by age categories are shown in Figure 1 . In female cattle the mortality was highest in young calves under 3 months of age $(M R=27.70$ per 100 animal-years, 95\% CI 26.99; 28.43) and lowest in $12-17$ months old heifers (MR $=0.99$ per 100 animal-years, 95\% CI $0.89 ; 1.10$ ), after this age category mortality rate increased. In males the MR was highest in the youngest age group ( $M R=55.96$ per 100 animal-years, 95\% CI 54.53; 57.42). Mortality rate declined in the following age categories whereas it was lowest in the oldest age category $(\geq 12$ months, $M R=2.59$ per 100 animal-years, 95\% CI 2.29; 2.93) (Figure 1).

\subsection{Farmers' stated reasons for on-farm mortality}

The main farmers' stated reasons for dairy cow unassisted death and euthanasia according to milk recording register were 'Metabolic and digestive disorders' (40.1\% of mortality cases) and 'Feet/claw disorders' (23.6\%). We were able to identify reasons for 11,412 on-farm deaths among cows whereas the number of euthanasia was 318 (2.8\%). Euthanasia was mostly done in case of 'Feet/claw disorders', 'Metabolic and digestive disorders' and 'Trauma and accident' (Table 1).

The main reasons for heifer unassisted death and euthanasia were 'Metabolic and digestive disorders' (43.2\%), 'Respiratory and infectious diseases' (26.8\%) and 'Other reasons' (11.8\%). Euthanasia was executed in $124(1.4 \%)$ of mortality cases and it was mostly executed in conditions under categories 'Trauma and accident', 'Metabolic and digestive disorders', 'Other reasons' and 'Unknown reasons' (Table 1).

Main farmers' stated reasons for unassisted death and euthanasia among young bulls were 'Metabolic and digestive disorders' (55.2\%) and 'Respiratory and infectious diseases' (23.5\%). In bulls, euthanasia was executed in $78(1.3 \%)$ of death events and most commonly due to 'Unknown reasons', 'Trauma and accident' and 'Other reasons' (Table 1).

\subsection{Risk factors for on-farm mortality}

In Model I (calves $<3$ months of age) an interaction between sex and breed was present. The highest mortality hazard occurred in Estonian Holstein bull calves (Hazard rate ratio $(\mathrm{HR})=1.97,95 \% \mathrm{CI}$ $1.89 ; 2.05, \mathrm{P}<0.001)$ and Estonian Red bull calves $(\mathrm{HR}=1.75,95 \%$ CI 1.59; 1.92, $\mathrm{P}<0.001)$ compared to baseline group female Estonian Holstein calves. There were no differences in mortality hazard between breeds in female calves. A significantly higher hazard of mortality was confirmed in Estonian Red male calves compared to Estonian Red female calves (HR = 1.68, 95\% CI $1.53 ; 1.85, \mathrm{P}<0.001)$. Compared to male Estonian Holstein calves male Estonian Red calves 
had significantly lower mortality hazard $(\mathrm{HR}=0.89,95 \% \mathrm{CI} 0.81 ; 0.97, \mathrm{P}=0.010)$ (data not shown). All herd size categories with more than 400 animal-years were associated with significantly higher hazard of mortality compared to smaller herds (Table 2).

In model II (youngstock aged 3-23 months) an interaction between age category and sex was present. Hazard of mortality was highest in female cattle aged 3-11 months being the baseline category in the model, followed by male cattle aged $3-23$ months $(\mathrm{HR}=0.76,95 \% \mathrm{CI} 0.68 ; 0.85)$. The lowest mortality hazard was present in female cattle aged $12-17$ months $(\mathrm{HR}=0.11,95 \% \mathrm{CI}$ $0.10 ; 0.13)$ compared to the reference group. The hazard of mortality was significantly higher in 18-23 months old female cattle compared to $12-17$ months old female cattle $(\mathrm{HR}=2.54,95 \% \mathrm{CI}$ $2.22 ; 2.92, \mathrm{P}<0.001)$. Male cattle aged $3-23$ months had higher mortality hazard compared to 18 23 months old females ( $\mathrm{HR}=2.67,95 \%$ CI $2.34 ; 3.04, \mathrm{P}<0.001$ ) (data not shown). Estonian Red breed cattle had lower mortality hazard (HR $=0.82,95 \%$ CI $0.70 ; 0.95)$ compared to Estonian Holstein breed animals. Regarding herd size the mortality hazard was significantly higher in herds over 400 animal-years. The hazard of mortality was lowest in Southwest region $(\mathrm{HR}=0.67,95 \%$ CI $0.52 ; 0.87$ ) compared to baseline category Northeast region (Table 3 ).

An interaction between herd size and age category was present in the risk factor analysis for onfarm mortality in cattle $\geq 24$ months (Model III). In both age groups (24-35 months and $\geq 36$ months) there was significantly higher mortality hazard in herds larger than 400 animal-years compared to smaller herds. In both age categories no difference in mortality hazard was present between herd size groups 400-899, 900-1499 and $\geq 1500$ animal-years. In herds with less than 400 animal-years mortality hazard was significantly higher in cattle aged $\geq 36$ months compared to 24-35 months old cattle $(\mathrm{HR}=1.41,95 \% \mathrm{CI} 1.26 ; 1.58)$ (Table 4$)$. Taking herd size into account, mortality hazard was significantly higher in older age group $\geq 36$ months compared to younger age category. Estonian Red breed cattle had lower mortality hazard ( $\mathrm{HR}=0.70,95 \%$ CI $0.65 ; 0.75)$ compared to animals of Estonian Holstein breed. The hazard of mortality was significantly lower in all regions compared to baseline category Northeast region (Table 4).

\subsection{Seasonal distribution of mortality}

Distribution of monthly mortality rates for the two-year' time period is presented in Figure 2. Calves aged $<3$ months had higher mortality hazard in January, February and March both years. In addition, August and December 2014 were also months with high mortality hazard for young calves. Heifers aged 3-11 months had highest mortality rates in August and September both years as well as in October 2013 and December 2014. Heifers aged 12-23 months the mortality hazard increased since March 2014 and stayed high during the second half-year of 2014. Among adult cattle ( $\geq 24$ months) the period with increased mortality rate was summer (months July to September) 2013. Mortality rate in adult cattle also increased considerably since December 2013 and stayed higher compared to the equivalent months in 2013 (Figure 2).

\subsection{Model Fit}

Fit of the Weibull model was confirmed with a straight line in the plot of Cox-Snell residuals and cumulative hazard. The proportional hazard assumption was confirmed with parallel curves of the predictor categories in the log-cumulative hazard plots. 


\section{Discussion}

\subsection{On-farm mortality of cattle in Estonian dairy herds}

For female cattle a reverse J-shaped pattern of mortality rate over animals' age is formed and this kind of pattern has been identified also in previous studies (Pannwitz, 2015). We identified a higher mortality among male cattle which can be related to biological features and lower market value (Raboisson et al., 2013; Pannwitz, 2015) and the fact that bull calves do not play a role in dairy herd replacement. The lowest hazard of mortality occurred among heifers aged 12-17 months. This is the age group in which calf-age diseases are no longer a threat, animals are adapted to their environment and they have achieved a certain immunity to the endemic infections. Also, this age group does not have the stress caused by calving and following lactation. This group of animals is frequently monitored to detect heat allowing fast detection of diseased animals. Female cattle aged 18-23 months had significantly higher mortality hazard compared to previous age group. Unfortunately, the calving date was not available in animal registry database, therefore we were unable to discriminate cow and heifer stages exactly. As some proportion of cows calve before 24 months of age an increased mortality hazard in that age category may be the consequence of including animals with higher early lactation mortality hazard (Alvasen et al., 2014).

In our study, mortality rates for female cattle aged 24-35 months and $\geq 36$ months were 4.0 and 6.5 per 100 animal-years, respectively. These results are comparable to what has been found in other studies e.g. 6.0 per 100 animal-years for dairy cows in Sweden (Alvåsen et al., 2012) and 6.4 per 100 animal-years in the USA (Shahid et al., 2015). Higher mortality among older cows can be explained by an increased risk of calving and production-related diseases cumulating with each parity (e.g. milk fever, displaced abomasum, downer cow syndrome, mastitis, uterine prolapse retained placenta and ketosis) (Thomsen et al, 2004; Shahid et al., 2015).

Comparison of the mortality estimates of our study with others work has revealed to be somewhat complicated. As mentioned before, there are only few studies reflecting the mortality levels on country level or larger regions. Most of the studies done in other countries are mainly focused on mortality in certain age-groups (Alvåsen et al., 2014). In addition, mortality can be calculated differently - some studies report mortality risk (Thomsen et al., 2004; Svensson et al., 2006; Raboisson et al., 2013), whereas others calculate mortality rate for different denominator (Raboisson et al., 2011; Perrin et al., 2012; Pannwitz, 2015). Also, registry data misses deaths that occur in the first days of life, since farmers often report calves who died during the first few days and not ear-tagged yet, as stillborn. Therefore the mortality rate presented for young calves in this study is underestimated.

\subsection{Farmers' stated reasons for on-farm mortality}

Farmers' stated main reasons for unassisted death or euthanasia of dairy cows were 'Metabolic and digestive disorders' and 'Feet/claw disorders'. Although it is known that farmers' perception of cause of death compared to necropsy examinations are incorrect in slightly more than half of the mortality cases (McConnel et al., 2009; Thomsen et al, 2012) our results are in concordance with a recent study in Sweden (Alvåsen et al., 2014). This implies that a herd health improvement plan should put more effort on prevention of these diseases in order to decrease mortality events in production herds. Euthanasia was executed in $2.8 \%$ of the on-farm mortality cases in Estonian dairy cows which is considerably lower than 58\% that was found in Denmark (Thomsen et al., 2004). In reporting mortality cases to EARIB the farmers could select between options 'death' and 
'emergency slaughter'. Questioning the animal registry and few farmers revealed that there might be some misunderstanding of the term 'emergency slaughter' and farmers prefer to report euthanized animals to be 'dead' in the EARIB database. Therefore the low proportion of euthanasias should be considered a reporting bias and should be interpreted accordingly.

For youngstock, around $80 \%$ of deaths could be attributed to 'Metabolic and digestive disorders' and 'Respiratory and infectious diseases', whereas most commonly these occur during the first four months of age. These results are similar to that found previously (Svensson et al., 2006; Gulliksen et al., 2009; Torsein et al., 2011; Raboisson et al., 2013) confirming the need for more effective herd health measures to combat these disorders.

Proportion of euthanasia for on-farm mortality cases was also very low in heifers (1.4\%) and young bulls $(1.3 \%)$. As far as we know, no publication about euthanasia in youngstock is published. Despite of that, underreporting euthanasia similarly to that in cows, is most possibly present in Estonian animal registry also for youngstock.

\subsection{Risk factors}

The risk factor analysis identified that Holstein breed was associated with higher mortality hazard which has also been identified in previous studies (Thomsen et al., 2006; Raboisson et al., 2011; Alvåsen et al., 2012; Shahid et al., 2015). In Estonia, Holstein breed cows have higher milk yield compared to Estonian Red cows (Estonian Animal Recording Yearbook 2015). Higher milk yield has been found to be a risk factor for mortality (Miller et al., 2008; Alvåsen et al., 2014). Also, previous studies have reported that Holstein breed animals are more susceptible to productionrelated diseases (Persson Waller et al., 2009).

Mortality has been reported to increase with herd size in several studies (Thomsen et al., 2006; McConnel et al., 2008; Shahid et al., 2015). Our results show that herds with $<400$ animal-years differ significantly from herds with $>400$ animal-years by having significantly lower mortality hazard in all age groups. In larger herds, individual attention of animals is reduced, also larger herds have different housing conditions and mechanization compared to smaller farms (Raboisson et al., 2011). Furthermore, among herds with $<400$ animals most are family farms and less or no paid labour is used to manage the farms, which might be favourable for the attention towards the animals. Also, grazing is rare in Estonia, especially in larger herds, which has been previously identified as a risk factor for mortality (Thomsen et al., 2006). Herd size is a proxy to other risk factors and further studies should specify more detailed risk factors reflected by herd size.

Regional differences in mortality hazard were confirmed for cattle over three months of age and 'region' acted as a confounder in all three models. Due to the small size of Estonia, the climatic conditions are relatively even but herd management factors may differ by location. Therefore a further study including herds distributed across Estonia and including characteristics of farm housing and management should reveal the factors behind the regional differences in mortality.

Significant clustering of mortality hazard was confirmed by the significant frailty term for herd. As the study also included small herds the clustering may partly arise from the extreme mortality levels in those herds. The between-herd variance was highest for young calves $(<3$ months of age $)$ and lowest for adult cattle $\geq 24$ months. This means that some farms achieve relatively low mortality in calves whereas some herds have very poor calf performance resulting in high mortality. This confirms the results of Raboisson et al. (2013) who found high standard deviations for herd level 
mortality rates and concluded that it is possible for the farmers to achieve very low mortality rates also in animal categories known to have a high risk of mortality. Further studies should clarify the factors that determine the herd performance related with cattle mortality of different age groups.

According to the shape parameters of Models I, II and III the hazard function decreased monotonically for young calves (shape parameter $p=0.79$ ) and less for 3-23 months old youngstock (shape parameter $p=0.92$ ). In adult cattle the shape parameter was 1.13 meaning that the hazard function was monotonically increasing, but at a decreasing rate (Dohoo et al., 2009).

\subsection{Seasonality}

Seasonal distributions of mortality differed in four age categories. Higher morality in dairy calves during winter period has been identified in previous studies and it is believed that low temperature and more intensive infectious disease spread may conduce to higher mortality (Svensson et al., 2006; Bleul, 2011; Raboisson et al., 2013). Youngstock aged 3-11 months had higher mortality during autumn months. Reasons for this finding are difficult to provide, we may speculate that at the end of the grazing period there is less feed available in the pastures and animals are more susceptible to pasture parasite infections. Moving animals to the barns at the end of the grazing period may also induce higher stress level predisposing to morbidity and mortality.

Considerable increase in mortality of youngstock 12-23 months and cattle $\geq 24$ months occurred since March 2014 and December 2013, respectively. Reasons for this finding are difficult to provide but analysis of further years should reveal whether gradual increase occurs in dairy cattle mortality in Estonia or the observed increase was a temporary fluctuation.

A somewhat higher mortality rate was observed in the oldest age group during summer months. With warm and moist weather it is plausible that heat stress may affect the resistance of cows and can be a cause of higher mortality (Bishop-Williams et al., 2015). 


\section{Conclusions}

The present study identified mortality rate in Estonian dairy herds that is roughly comparable with studies of other countries. The study highlights the necessity to put more effort in prevention of metabolic and digestive tract diseases and feet and claw disorders in cows in order to reduce mortality and improve animal welfare. To ensure health and welfare in youngstock it is important to contribute to prevention of diarrhoea and respiratory diseases. We identified that the mortality differs between breeds, sex and season. Herd size and region are significant factors associated with cattle mortality but rather reflect other direct factors influencing mortality. For specific detection of risk factors it is necessary to carry out further research.

\section{Conflicts of interest}

There are no conflicts of interest.

\section{Acknowledgments}

The authors thank Olle Antson (Estonian Agricultural Registers and Information Board) and Inno Maasikas (Estonian Livestock Performance Recording Ltd) for data inquiry. This project was funded by the Estonian University of Life Sciences Strategic Development Fund [contract no 8M160114VLVM]. 


\section{References}

Alvåsen, K., Jansson Mörk, M., Hallén Sandgren, C., Thomsen, P.T., Emanuelson, U., 2012. Herdlevel risk factors associated with cow mortality in Swedish dairy herds. J Dairy Sci. 95:4352-4362.

Alvåsen, K., Jansson Mörk, M., Dohoo, I.R., Sandgren, C.H., Thomsen, P.T., Emanuelson, U., 2014. Risk factors associated with on-farm mortality in Swedish dairy cows. Prev Vet Med. 117, 110-120.

Azizzadeh, M., Shooroki, H.F., Kamalabadi, A.S., Stevenson, M.A., 2012. Factors affecting calf mortality in Iranian Holstein dairy herds. Prev Vet Med. 104, 335-340.

Bishop-Williams, K.E., Berke, O., Pearl, D.L., Hand, K., Kelton, D.F., 2015. Heat stress related dairy cow mortality during heat waves and control periods in rural Southern Ontario from 20102012. BMC Vet Res. 11:291.

Bleul, U., 2011. Risk factors and rates of perinatal and postnatal mortality in cattle in Switzerland. Livestock Sci. 135:257-264.

Burow, E., Thomsen, P.T., Sørensen, J.T., Rousing, T., 2011. The effect of grazing on cow mortality in Danish dairy herds. Prev Vet Med. 100, 237-241.

Dohoo, I., Martin, W., Stryhn, H., 2009. Logistic Regression. Modelling Survival data. In: Veterinary Epidemiologic Research, $2^{\text {nd }}$ ed. VER Inc., Charlottetown, Canada, pp. 395-426, 467527.

Estonian Animal Recording Yearbook 2015. Jõudluskontrolli aastaraamat 2015 (in Estonian). Retrieved from: https://www.jkkeskus.ee/jkk/piimaveised/statistika/j\%C3\%B5udluskontrolliaastaraamatud/. Date accessed: 19.08.2016.

Eurostat, 2015. Milk and milk product statistics. Retrieved from: http://ec.europa.eu/eurostat/statistics-

explained/index.php/Milk_and_milk_product_statistics\#Milk_production. Date accessed: 29.08.2016.

Gulliksen, S.M., Lie, K.I., Løken, T., Østerås, O., 2009. Calf mortality in Norwegian dairy herds. J Dairy Sci. 92, 2782-2795.

Losinger, W.C., Heinrichs, A.J., 1997. Management practices associated with high mortality among preweaned dairy heifers. J Dairy Res. 64, 1-11.

McConnel, C.S., Lombard, J.E., Wagner, B.A., Garry, F.B., 2008. Evaluation of factors associated with increased dairy cow mortality on United States dairy operations. J Dairy Sci. 91, 1423-1432.

McConnel, C.S., Garry, F.B., Lombard, J.E., Kidd, J.A, Hill, A.E., Gould, D.H., 2009. A necropsybased descriptive study of dairy cow deaths on a Colorado dairy. J Dairy Sci. 92, 1954-1962.

Miller, R.H., Kuhn, M.T., Norman, H.D., Wright, J.R., 2008. Death losses for lactating cows in herds enrolled in dairy herd improvement test plans. J Dairy Sci. 91, 3710-3715.

Ortiz-Pelaez, A., Pritchard, D.G., Pfeiffer, D.U., Jones, E., Honeyman, P., Mawdsley, J.J., 2008. Calf mortality as a welfare indicator on British cattle farms. Vet J. 176, 177-181.

Pannwitz, G., 2015. Standardized analysis of German cattle mortality using national register data. Prev Vet Med. 118, 260-270. 
Persson Waller, K., Bengtsson, B., Lindberg, A., Nyman, A., Ericsson Unnerstad, H., 2009. Incidence of mastitis and bacterial findings at clinical mastitis in Swedish primiparous cows Influence of breed and stage of lactation. Vet Microbiol. 134, 89-94.

Raboisson, D., Cahuzac, E., Sans, P., Allaire, G., 2011. Herd-level and contextual factors influencing dairy cow mortality in France in 2005 and 2006. J Dairy Sci. 94, 1790-1803.

Raboisson, D., Delor, E., Cahuzac, E., Gendre, C., Sans, P., Allaire, G., 2013. Perinatal, neonatal and rearing period mortality of dairy calves and replacement heifers in France. J Dairy Sci. 96, 2913-2924.

Riigi Teataja, 1999. Loomatauditõrje seadus (Animal Disease Control Act). Riigi Teataja, 57, 598 (in Estonian). Retrieved from: https://www.riigiteataja.ee/akt/101092015020?leiaKehtiv Date accessed: 04.05.2016.

Santman-Berends, I.M.G.A., Buddiger, M., Smolenaars, A.J.G., Steuten, C.D.M., Roos, C.A.J., Van Erp, A.J.M., Van Schaik, G., 2014. A multidisciplinary approach to determine factors associated with calf rearing practices and calf mortality in dairy herds. Prev Vet Med. 117, 375387.

Santman-Berends, I.M.G.A., Brouwer-Middelesch, H., Van Wuijckhuise, L., de Bont-Smolenaars, A.J.G., Van Schaik, G., 2016. Surveillance of cattle health in the Netherlands: Monitoring trends and developments using routinely collected cattle census data. Prev Vet Med. 134, 103-112.

Shahid, M.Q., Reneau, J.K., Chester-Jones, H., Chebel, R.C., Endres, M.I., 2015. Cow- and herdlevel risk factors for on-farm mortality in Midwest US dairy herds. J Dairy Sci. 98, 1-13.

Struchen, R., Reist, M., Zinsstag, J., Vial, F., 2015. Investigating the potential of reported cattle mortality data in Switzerland for syndromic surveillance. Prev Vet Med. 121,1-7.

Svensson, C., Linder, A., Olsson, S.-O., 2006. Mortality in Swedish dairy calves and replacement heifers. J Dairy Sci. 89, 4769-4777.

The Estonian Agricultural Registers and Information Board. Data enquiry from: www.pria.ee. Date accessed: 13.06 .2016

Thomsen, P.T., Kjeldsen, A.M., Sørensen, J.T., Houe, H., 2004. Mortality (including euthanasia) among Danish dairy cows (1990-2001). Prev Vet Med. 62, 19-33.

Thomsen, P.T., Houe, H., 2006. Dairy cow mortality. A review. Vet Q. 28, 122-129.

Thomsen P.T., Kjeldsen, A.M., Sorensen, J.T., Houe, A., Ersboll, A.K., 2006. Herd-level risk factors for the mortality of cows in Danish dairy herds. Vet Rec. 158, 622-626.

Thomsen, P.T., Dahl-Pedersen, K., Jensen, H.E., 2012. Necropsy as means to gain additional information about causes of dairy cow deaths. J Dairy Sci. 95, 5798-5803.

Torres, G, Ciaravino, V., Ascaso, S., Flores, V., Romero, L., Simón, F., 2015. Syndromic surveillance system based on near real-time cattle mortality monitoring. Prev Vet Med. 119, 216221.

Torsein, M., Lindberg, A., Hallen Sandgren, C., Persson Waller, K., Törnquist, M., Svensson, C., 2011. Risk factors for calf mortality in large Swedish dairy herds. Prev Vet Med. 99, 136-147. 
Table 1. Descriptive statistics of farmer's stated reasons for on-farm mortality of Estonian dairy cattle in 2013 and 2014

\begin{tabular}{|c|c|c|c|c|c|}
\hline Reason of exit & $\begin{array}{c}\mathrm{n} \\
\text { (total) }\end{array}$ & $(\%)$ & $\begin{array}{c}n \\
\text { (euthanasia) }\end{array}$ & $\begin{array}{c}\mathrm{n} \\
\text { (unassisted death) }\end{array}$ & $\begin{array}{c}\text { Median age in months } \\
\text { (quartiles) }\end{array}$ \\
\hline \multicolumn{6}{|l|}{ cows } \\
\hline Feet/claw disorders & 2,687 & 23.6 & 137 & 2,550 & $52.2(37.5 ; 70.1)$ \\
\hline $\begin{array}{l}\text { Respiratory and infectious } \\
\text { diseases }\end{array}$ & 336 & 2.9 & 1 & 335 & $48.8(35.4 ; 65.4)$ \\
\hline $\begin{array}{l}\text { Metabolic and digestive } \\
\text { disorders }\end{array}$ & 4,570 & 40.1 & 70 & 4,500 & $59.8(43.9 ; 76.6)$ \\
\hline Fertility problems & 253 & 2.2 & 5 & 248 & $54.8(39.7 ; 74.2)$ \\
\hline Dystocia & 617 & 5.4 & 13 & 604 & $51.6(29.8 ; 73.3)$ \\
\hline Trauma and accident & 1,067 & 9.3 & 43 & 1,024 & $53.8(38.8 ; 72.4)$ \\
\hline Udder disorders & 824 & 7.2 & 17 & 807 & $56.4(42.3 ; 72.8)$ \\
\hline Other & 1,010 & 8.9 & 22 & 988 & $58.0(41.7 ; 77.8)$ \\
\hline Unknown reasons & 48 & 0.4 & 10 & 38 & 93.8 (61.9; 119.3) \\
\hline Total & 11,412 & 100.0 & 318 & 11,094 & $56.3(40.2 ; 74.5)$ \\
\hline \multicolumn{6}{|l|}{ HEIFERS $^{a}$} \\
\hline Feet/claw disorders & 204 & 2.3 & 4 & 200 & $3.4(1.1 ; 17.3)$ \\
\hline $\begin{array}{l}\text { Respiratory and infectious } \\
\text { diseases }\end{array}$ & 2,387 & 26.8 & 13 & 2,374 & $1.9(0.7 ; 3.9)$ \\
\hline $\begin{array}{l}\text { Metabolic and digestive } \\
\text { disorders }\end{array}$ & 3,848 & 43.2 & 24 & 3,824 & $0.5(0.3 ; 1.8)$ \\
\hline Fertility problems & 33 & 0.4 & 3 & 30 & $25.6(22.4 ; 30.6)$ \\
\hline Trauma and accident & 862 & 9.7 & 36 & 826 & $10.9(3.2 ; 21.1)$ \\
\hline Other & 1,055 & 11.8 & 24 & 1,031 & $2.5(0.5 ; 8.8)$ \\
\hline Unknown reasons & 516 & 5.8 & 20 & 496 & $25.4(23.5 ; 27.8)$ \\
\hline Total & 8,905 & 100.0 & 124 & 8,781 & $1.5(0.43 ; 6.1)$ \\
\hline \multicolumn{6}{|l|}{ YOUNG BULLS } \\
\hline Feet/claw disorders & 166 & 2.8 & 2 & 164 & $1.1(0.6 ; 2.9)$ \\
\hline $\begin{array}{l}\text { Respiratory and infectious } \\
\text { diseases }\end{array}$ & 1,430 & 23.5 & 4 & 1,426 & $0.7(0.4 ; 1.9)$ \\
\hline $\begin{array}{l}\text { Metabolic and digestive } \\
\text { disorders }\end{array}$ & 3,357 & 55.2 & 5 & 3,352 & $0.4(0.3 ; 0.6)$ \\
\hline Trauma and accident & 311 & 5.1 & 22 & 289 & $2.5(0.6 ; 12.4)$ \\
\hline Other & 567 & 9.3 & 20 & 547 & $0.5(0.3 ; 1.2)$ \\
\hline Unknown reasons & 250 & 4.1 & 25 & 225 & $0.6(0.3 ; 1.1)$ \\
\hline Total & 6,081 & 100.0 & 78 & 6,003 & $0.5(0.3 ; 1.0)$ \\
\hline
\end{tabular}

${ }^{a}$ Female cattle from birth to first calving

${ }^{\mathrm{b}}$ Male cattle from birth to first registered breeding event 
Table 2. Risk factors for on-farm dairy calf (less than 3 months) mortality identified in a multivariable Weibull proportional hazard random effect model evaluated in 192,081 calves from 1,577 herds in Estonia in 2013 and 2014

\begin{tabular}{|c|c|c|c|c|c|c|c|}
\hline Variable & Category & $\mathrm{n}$ & $\mathrm{MR}^{\mathrm{a}}$ & $\begin{array}{c}\text { Hazard rate ratio } \\
(\mathrm{HR})\end{array}$ & $\begin{array}{c}95 \% \text { Confidence } \\
\text { interval of HR }\end{array}$ & P-value & $\begin{array}{c}\text { Wald test } \mathrm{P} \text { - } \\
\text { value }\end{array}$ \\
\hline \multirow[t]{6}{*}{ Sex x Breed } & Female, Estonian Holstein & 77,131 & 28.69 & 1 & & & $<0.001$ \\
\hline & Male, Estonian Holstein & 76,207 & 61.78 & 1.97 & $1.89 ; 2.05$ & $<0.001$ & \\
\hline & Female, Estonian Red & 17,114 & 24.45 & 1.04 & $0.95 ; 1.14$ & 0.426 & \\
\hline & Male, Estonian Red & 17,430 & 42.16 & 1.75 & $1.59 ; 1.92$ & $<0.001$ & \\
\hline & Female, Other ${ }^{b}$ & 2,041 & 17.74 & 1.23 & $0.97 ; 1.55$ & 0.086 & \\
\hline & Male, Other ${ }^{b}$ & 2,158 & 18.97 & 1.38 & $1.09 ; 1.75$ & 0.007 & \\
\hline \multirow{4}{*}{$\begin{array}{c}\text { Herd size (animal- } \\
\text { years) }\end{array}$} & $<400$ & 43,369 & 15.69 & 1 & & & $<0.001$ \\
\hline & $400-899$ & 45,984 & 43.96 & 4.41 & $3.24 ; 6.00$ & $<0.001$ & \\
\hline & $900-1499$ & 56,641 & 45.91 & 4.67 & $3.20 ; 6.81$ & $<0.001$ & \\
\hline & $\geq 1500$ & 46,087 & 43.12 & 4.36 & $2.45 ; 7.78$ & $<0.001$ & \\
\hline \multirow[t]{4}{*}{ Region ${ }^{c}$} & Northeast & 78,513 & 43.53 & 1 & & & 0.279 \\
\hline & Southeast & 42,294 & 32.07 & 0.89 & $0.68 ; 1.16$ & 0.381 & \\
\hline & Southwest & 45,122 & 34.50 & 0.77 & $0.60 ; 1.00$ & 0.051 & \\
\hline & Northwest & 26,152 & 31.16 & 0.85 & $0.64 ; 1.13$ & 0.259 & \\
\hline
\end{tabular}

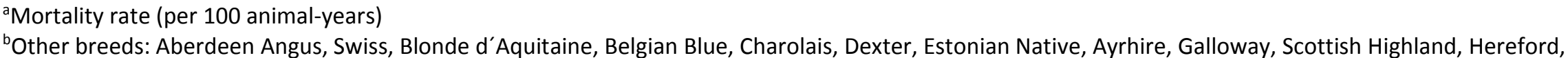
Jersey, Limousine, Piemontese, Bison, German Shorthorn, Simmental

'Northeast Estonia: Ida-Viru, Lääne-Viru, Jõgeva, Järva county; Southeast Estonia: Tartu, Valga, Võru, Põlva county; Southwest Estonia: Pärnu, Viljandi, Saare county; Northwest Estonia: Harju, Rapla, Lääne, Hiiu county

Variance parameter for herd $1.48(95 \% \mathrm{Cl} 1.22 ; 1.79)$, shape parameter $\mathrm{p}=0.79$ 
Table 3. Risk factors for on-farm dairy cattle (3-23 months old) mortality identified in a multivariable Weibull proportional hazard random effect model evaluated in 171,771 cattle from 2,054 herds in Estonia in 2013 and 2014

\begin{tabular}{|c|c|c|c|c|c|c|c|}
\hline Variable & Category & $\mathrm{n}^{\mathrm{ab}}$ & $\mathrm{MR}^{\mathrm{c}}$ & $\begin{array}{c}\text { Hazard rate ratio } \\
(\mathrm{HR})\end{array}$ & $\begin{array}{c}\text { 95\% Confidence } \\
\text { interval of HR }\end{array}$ & P-value & $\begin{array}{c}\text { Wald test } P \text { - } \\
\text { value }\end{array}$ \\
\hline \multirow[t]{5}{*}{ Age category $x$ sex $^{b}$} & 3-11 months, Female & 89,585 & 5.16 & 1 & & & $<0.001$ \\
\hline & 12-17 months, Female & 91,673 & 0.52 & 0.11 & $0.10 ; 0.13$ & $<0.001$ & \\
\hline & 18-23 months, Female & 86,911 & 1.40 & 0.29 & $0.26 ; 0.32$ & $<0.001$ & \\
\hline & 3-23 months, Male & 50,484 & 3.06 & 0.76 & $0.68 ; 0.85$ & $<0.001$ & \\
\hline & & & & & & & $<0.001$ \\
\hline \multirow{5}{*}{$\begin{array}{l}\text { Herd size (animal- } \\
\text { years) }^{\mathrm{a}}\end{array}$} & & & & & & & \\
\hline & $<400$ & 47,588 & 1.41 & 1 & & & \\
\hline & $400-899$ & 39,164 & 2.06 & 1.98 & $1.52 ; 2.59$ & $<0.001$ & \\
\hline & $900-1499$ & 44,638 & 1.75 & 1.72 & $1.25 ; 2.37$ & 0.001 & \\
\hline & $\geq 1500$ & 40,381 & 1.75 & 1.66 & $1.03 ; 2.65$ & 0.036 & \\
\hline \multirow[t]{3}{*}{ Breed $^{a}$} & Estonian Holstein & 132,678 & 1.87 & 1 & & & 0.014 \\
\hline & Estonian Red & 34,160 & 1.23 & 0.82 & $0.70 ; 0.95$ & 0.008 & \\
\hline & Other ${ }^{d}$ & 4,933 & 1.44 & 0.80 & $0.60 ; 1.07$ & 0.128 & \\
\hline \multirow[t]{4}{*}{ Region ${ }^{\text {ae }}$} & Northeast & 69,866 & 1.95 & 1 & & & 0.027 \\
\hline & Southeast & 39,056 & 1.61 & 0.91 & $0.71 ; 1.17$ & 0.464 & \\
\hline & Southwest & 37,941 & 1.31 & 0.67 & $0.52 ; 0.87$ & 0.003 & \\
\hline & Northwest & 24,908 & 1.95 & 0.85 & $0.65 ; 1.12$ & 0.240 & \\
\hline
\end{tabular}

\footnotetext{
${ }^{a}$ Number of animals in each category
}

${ }^{b}$ Number of observations in each category after splitting the observations according to age categories

${ }^{c}$ Mortality rate (per 100 animal-years) in each category

dOther breeds: Aberdeen Angus, Swiss, Blonde d'Aquitaine, Belgian Blue, Charolais, Dexter, Estonian Native, Ayrhire, Galloway, Scottish Highland, Hereford, Jersey, Limousine, Piemontese, Bison, German Shorthorn, Simmental 


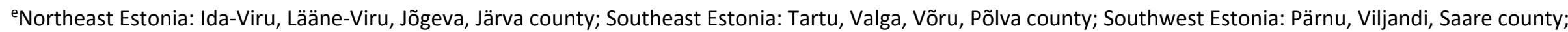
Northwest Estonia: Harju, Rapla, Lääne, Hiiu county

Variance parameter for herd $0.92(95 \% \mathrm{Cl} 0.72 ; 1.16)$, shape parameter $\mathrm{p}=0.92$ 
Table 4. Risk factors for on-farm adult dairy cattle ( $\geq 24$ months) mortality identified in a multivariable Weibull proportional hazard random effect model evaluated in 166,412 cattle from 2,419 herds in Estonia in 2013 and 2014

\begin{tabular}{|c|c|c|c|c|c|c|c|}
\hline Variable & Category & $\mathrm{n}^{\mathrm{ab}}$ & $\mathrm{MR}^{\mathrm{c}}$ & $\begin{array}{c}\text { Hazard rate } \\
\text { ratio (HR) }\end{array}$ & $\begin{array}{c}95 \% \\
\text { Confidence } \\
\text { intervall of HR }\end{array}$ & P-value & $\begin{array}{l}\text { Wald test } \mathrm{P} \text { - } \\
\text { value }\end{array}$ \\
\hline \multirow[t]{3}{*}{ Breed $^{\mathrm{a}}$} & Estonian Holstein & 129,310 & 6.48 & 1 & & & $<0.001$ \\
\hline & Estonian Red & 34,259 & 3.45 & 0.70 & $0.65 ; 0.75$ & $<0.001$ & \\
\hline & Other ${ }^{d}$ & 2,843 & 1.80 & 0.45 & $0.35 ; 0.59$ & $<0.001$ & \\
\hline \multirow{8}{*}{$\begin{array}{l}\text { Herd size (animal- } \\
\text { years) x age category }\end{array}$} & $<400,24-35$ months & 23,515 & 2.55 & 1 & & & $<0.001$ \\
\hline & $<400, \geq 36$ months & 34,093 & 3.60 & 1.41 & $1.26 ; 1.58$ & $<0.001$ & \\
\hline & $400-899,24-35$ months & 21,833 & 4.42 & 2.01 & $1.60 ; 2.52$ & $<0.001$ & \\
\hline & $400-899, \geq 36$ months & 28,646 & 7.71 & 3.41 & $2.75 ; 4.24$ & $<0.001$ & \\
\hline & 900-1499, 24-35 months & 27,118 & 4.74 & 2.17 & $1.67 ; 2.81$ & $<0.001$ & \\
\hline & $900-1499, \geq 36$ months & 34,132 & 7.49 & 3.23 & $2.51 ; 4.15$ & $<0.001$ & \\
\hline & $\geq 1500,24-35$ months & 22,706 & 4.28 & 1.93 & $1.33 ; 2.80$ & 0.001 & \\
\hline & $\geq 1500, \geq 36$ months & 27,656 & 7.79 & 3.23 & $2.24 ; 4.65$ & $<0.001$ & \\
\hline \multirow[t]{4}{*}{ Region $^{\text {ae }}$} & Northeast & 68,159 & 8.04 & 1 & & & $<0.001$ \\
\hline & Southeast & 34,650 & 4.17 & 0.65 & $0.55 ; 0.76$ & $<0.001$ & \\
\hline & Southwest & 39,248 & 3.69 & 0.68 & $0.58 ; 0.80$ & $<0.001$ & \\
\hline & Northwest & 24,355 & 5.14 & 0.74 & $0.61 ; 0.89$ & 0.001 & \\
\hline
\end{tabular}

\footnotetext{
${ }^{a}$ Number of animals in each category

${ }^{b}$ Number of observations in each category after splitting the observations according to age categories

${ }^{c}$ Mortality rate (per 100 animal-years) in each category
} 
'Other breeds: Aberdeen Angus, Blonde d'Aquitaine, Belgian Blue, Charolais, Dexter, Estonian Native, Ayrhire, Galloway, Scottish Highland, Hereford, Jersey, Limousine, Piemontese, Bison, German Shorthorn, Simmental

'Northeast Estonia: Ida-Viru, Lääne-Viru, Jõgeva, Järva county; Southeast Estonia: Tartu, Valga, Võru, Põlva county; Southwest Estonia: Pärnu, Viljandi, Saare county; Northwest Estonia: Harju, Rapla, Lääne, Hiiu county

Variance parameter for herd $0.54(95 \% \mathrm{Cl} 0.44 ; 0.67)$, shape parameter $\mathrm{p}=1.13$ 

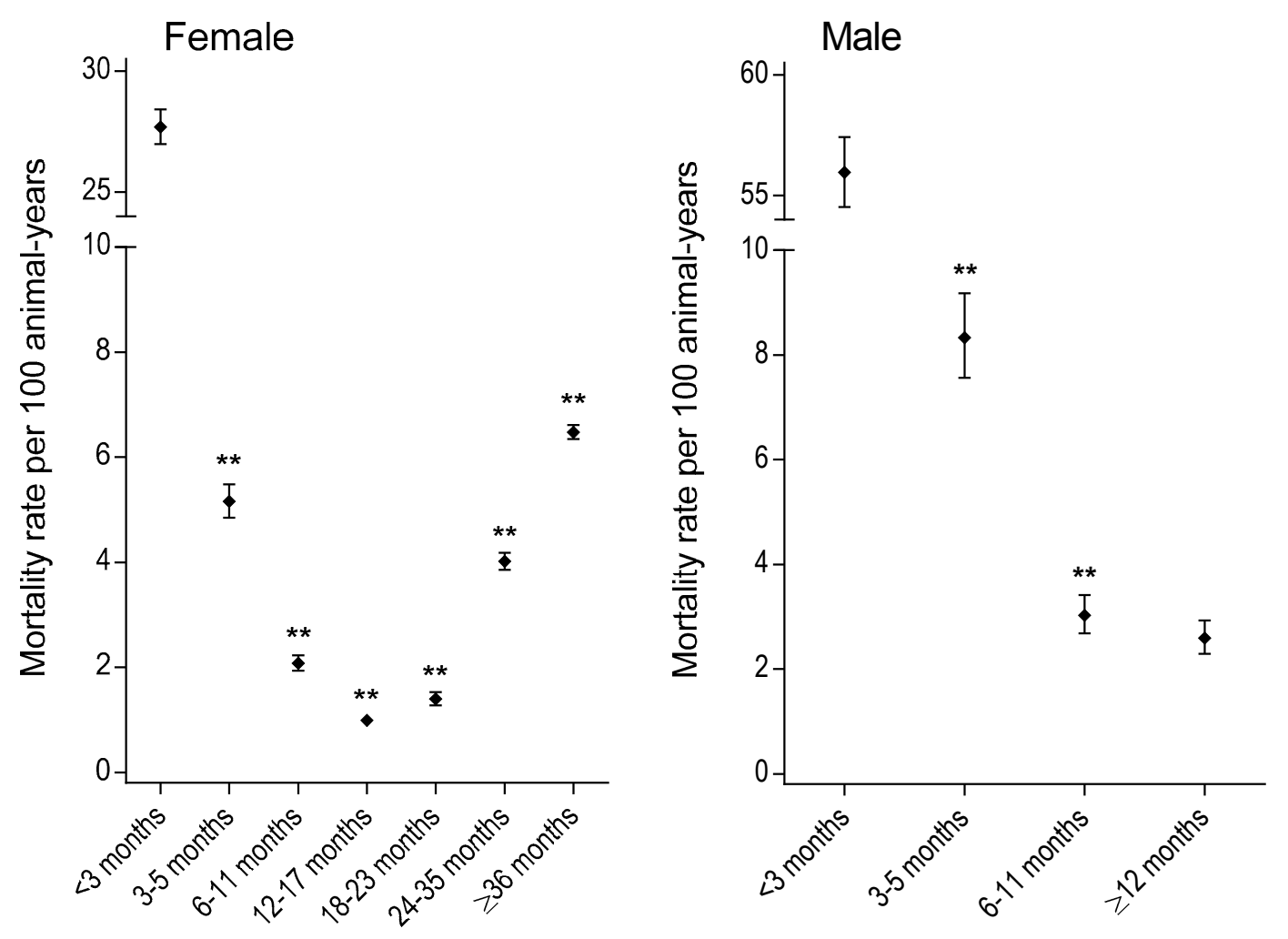

Figure 1. Mortality rate estimates in female and male cattle of Estonian dairy herds by age group.

** $\mathrm{P}<0.001$ compared to preceding age category in Weibull proportional hazards model with farm frailty effect. 

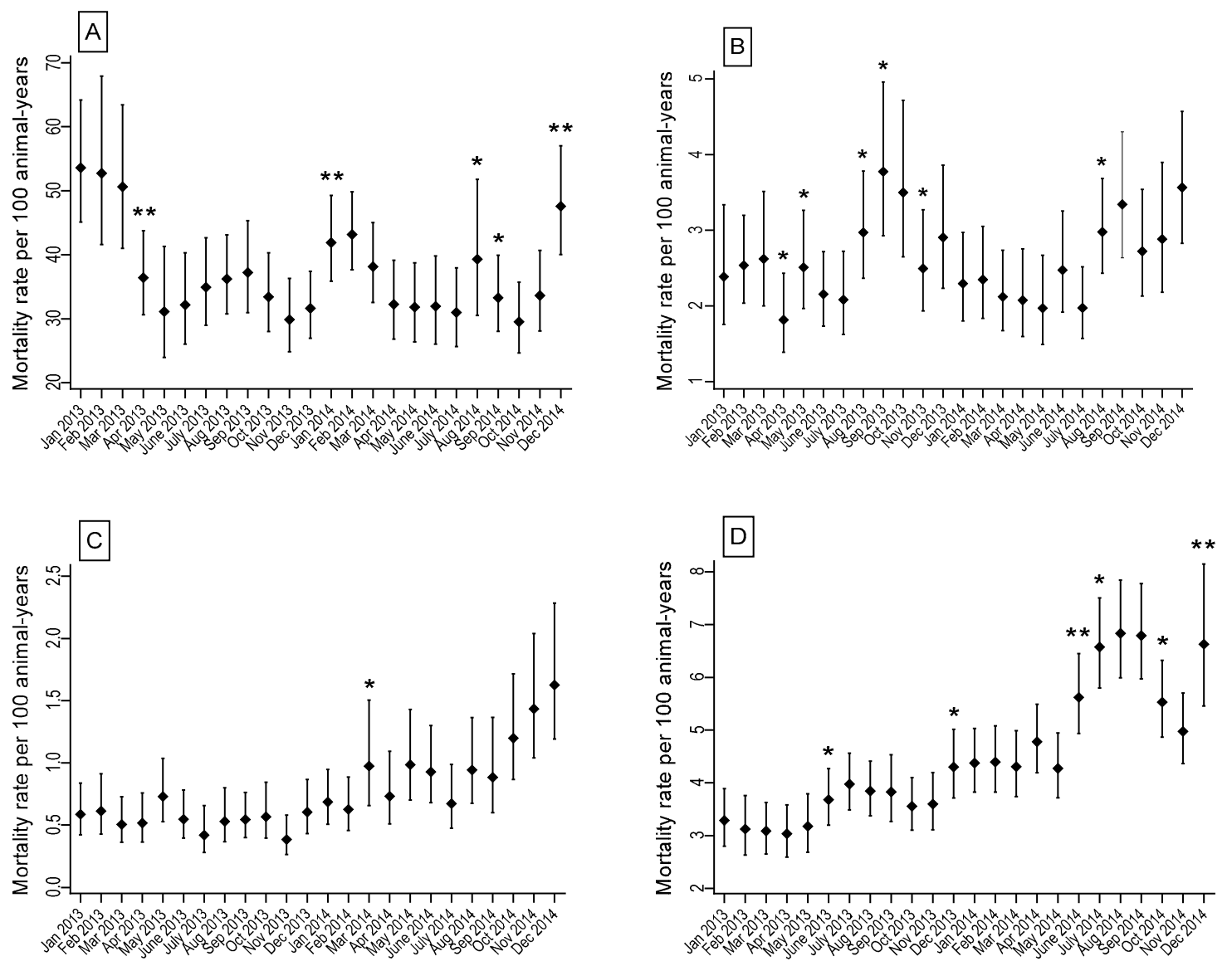

Figure 2. Seasonal distribution of mortality rate among four age groups: A - calves up to three months, B - youngstock 3-11 months, $\mathrm{C}$ - cattle 12-23 months, D - cattle $\geq 24$ months.

${ }^{*} \mathrm{P}<0.05$ and ${ }^{* *} \mathrm{P}<0.001$ compared to previous month in Weibull proportional hazards model 